\title{
Fostering Internationalisation in Higher Education by Virtual Mobility
}

\author{
Margarita Tereseviciene - Airina Volungeviciene - Estela \\ Dauksiene*
}

\begin{abstract}
The concept of virtual mobility and its characteristics are presented. Most definitions which consider virtual mobility from the educational perspective describe it as a form of learning, research, communication, and collaboration, but also as a form of mobility, which can be a supplement or substitute for physical mobility.

Based on the theoretical dispositions a study module "Learning in Higher Education" was created and delivered by an international, multiinstitutional group of teachers to an international, multi-institutional group of students. The virtual mobility case, research design, and data analysis, are presented. The results demonstrate the importance of virtual mobility in promoting international communication and developing communication skills with people from other countries, cultures as well as impact of internationalisation on higher educational institutions.
\end{abstract}

Key words: internationalisation, virtual mobility, communicative and collaborative learning.

Virtual mobility $(\mathrm{VM})$ is rather a new phenomenon and has been influenced very much by the development of ICT; however, virtual mobility also encourages institutions to adapt and further develop their pedagogical models: the change in content delivery and the change of learning tools require changes in pedagogy and didactical models (Bijnens, H. and Op de Beeck, I., 2006). VM facilitates intercultural experience between students and their staff, through the organization of trans-border discussion groups, international seminars, or by setting up of an international learning community; whereby staff and students acquire interpersonal and intercultural skills and get a chance to broaden their

\footnotetext{
* Margarita Tereseviciene, Vytautas Magnus University, Lithuania; m.teresevicienè@smf.vdu.lt

Airina Volungeviciene, Vytautas Magnus University, Lithuania; a.volungeviciene@isi.vdu.lt

Estela Dauksiene, Vytautas Magnus University, Lithuania; e.dauksiene@smf.vdu.lt
} 
cultural, social and political boundaries. By providing supplementary courses virtual mobility enables students to further individualize and specialize their portfolios.

The aim of the research is to define virtual mobility as a communicative and collaborative learning activity of students and teachers and to explain its contribution towards the internationalisation of higher education.

\section{Virtual mobility and internationalisation}

The first notions of virtual mobility (VM) arose in the last decades of the 20th century and at the beginning of the $21^{\text {st }}$, in some research papers (Bunt-Kokhuis, 1996, 2001, Van der Wende, 1998) and project result reports (Boninsegna and Dondi, 1998; Spot+ project team, 2001, Valiuškeviciute et al., 2006). BuntKokhuis $(1996,2001)$ created a rather interesting though idiosyncratic definition of $\mathrm{VM}$, where it is described as "the collaborative communication between a faculty member and his/her counterpart(s) mediated by a computer. More often, these meetings will be interactive and take place across national borders and across time zones". Boninsegna and Dondi (1998) characterize virtual mobility with the following elements "Trans-national lectures and/or learning materials, Cross-border recruitment of students, Intensity of communication flows, International accreditation of achievements, Multilingualism, Complementarities to both physical mobility and conventional teaching" and stress that "virtual mobility includes all forms that are communication intensive and run at international level." (Boninsegna and Dondi, 1998, p. 7)

Van der Wende (1998) defined virtual mobility in terms of an emerging form of internationalization where students follow courses offered by institutions abroad and interact with students and teachers, libraries and databases, in other countries. She promoted use of ICT for expanding the possibilities for cooperation and competition between institutions, and for providing students and academic teachers who are not able to travel extensively, with opportunities to benefit from internationalization. She also noticed the relationship with the idea of virtual mobility, flexible knowledge delivery and the new educational paradigm for e-learning or distance education.

The Coimbra Group collaboration, based on the research carried out during the VICTORIOUS project (Haywood et al., 2007), stressed the intercultural aspect and explained virtual mobility as the "use of the internet to enable learners to take courses and participate in local communities at a remote physical university without need to go to it directly. It often implies more than just taking courses but being able to access some of the cultural aspects" (p. 70). A more full-scale interpretation, which includes the intercultural aspect of VM, in order to "highlight the richness of the experience and the similarities with the Erasmus exchange programme" (Op de Beeck et al., 2007, p. 18) is provided in the 
Virtual Mobility Best-Practice Manual (Bijnens et al., 2006): "Virtual Mobility is a form of learning which consists of virtual components through an ICT supported learning environment that includes cross-border collaboration with people from different backgrounds and cultures working and studying together, having, as its main purpose, the enhancement of intercultural understanding and the exchange of knowledge". The existing definitions were extended in the Move-IT project and rephrased "as a set of ICT-supported activities that realize cross-border, collaborative experiences in a context of teaching and/or learning. These activities can take place in a fully ICT supported learning environment or as a complement to physical mobility (before, during and after). They can be aimed at the (practical) organization of the learning process or they can consist of actual teaching and/or learning activities. Virtual Mobility activities can cross borders between regions, countries, cultures and languages, but also between disciplines. Virtual mobility activities enable collaborative learning (i.e. learning from and with each other) and are always aimed at inter-cultural experiences" (Vriens et al., 2010, pp. 1-2).

Pawlowski, Holtkamp and Kalb (2010), describing internationalization competences, distinguish between internationalization and domain specific competences. Internationalization competences are seen as supporting competences to enable individuals to apply their domain knowledge in an international setting. Internationalization competences include intercultural competences in particular, which often can also be seen as an informal learning outcome of mobility, ICT competences, communication competences, collaboration competences and project management competences.

Summarizing the above mentioned definitions that analyse the concepts of virtual mobility and internationalization, the following characteristics of virtual mobility can be distinguished - the cooperation of universities as well as students and teachers; international study experience with the stress on cultural aspects, and different kinds of activities that lead to virtual mobility. It is important to highlight that although most of the definitions which consider virtual mobility from the educational perspective describe it as a form of learning or collaboration, they also stress that it is a form of mobility, which can be a supplement or substitute for physical mobility.

Analysing different resources, various virtual mobility characteristics or elements can be described, and they refer to the typology of virtual mobility activities, mainly constituted of virtual seminars, courses or programmes, virtual internship and virtual activities to support or extend physical mobility. Summarizing virtual mobility practices and concepts, as defined by various authors and project consortiums, virtual mobility can be defined as an activity or a form of learning, research, communication and collaboration, based on the following characteristics: 
* cooperation of at least 2 higher education institutions;

* virtual components through an ICT supported learning environment;

* collaboration of people from different background and cultures working and studying together, creating a virtual community;

* a clear goal and clearly defined learning outcomes;

* exchange of knowledge and improvement of intercultural competences as its main purpose;

* as a result of which the participants may obtain ECTS credits and/or its academic recognition will be assumed by the home university;

* visibility of university in higher education area;

* integration of ICT into their mainstream academic and business processes.

It is seen that virtual mobility enables universities to cooperate at a variety of levels. The main virtual mobility feature to be noted here is that virtual study course(s) or a programmes can be designed and/or provided for students by more than one host university and that is not usually the case in physical mobility. Organizing virtual mobility this way the students can attend course(s) from different institutions, study and work collaboratively in a more diverse international group, gaining experience in dealing with cultural differences of more than one country. New European initiatives (UbiCamp, 2012; VMCOLAB, 2012) make further steps in developing joint virtual mobility activities to provide students and teachers with cultural background and enriched university environment elements (multilingualism, virtual tours, virtual mobility supportkits) so that students have more similar cultural advantages to those involved in a real mobility and intercultural experience. Both academic and cultural content becomes equally important for students and higher education institutions.

\section{Case presentation}

The virtual mobility case (Fig. 1) represented and analysed in this paper had been prepared by the interuniversity team and had been implemented as the study module "Virtual Learning in Higher Education". The preparation team consisted of 13 teachers, who were delivering the module and there were 29 virtual mobility session participants from the following higher education institutions - University of Aveiro (Portugal), Jyväskylä University (Finland), UNIOVI-University of Oviedo (Spain), Jagiellonian University (Poland), BETI (represented by students of KTU, Lithuania), and Vytautas Magnus University (Lithuania) - attending the module. 
Figure $1 \quad$ Virtual mobility case

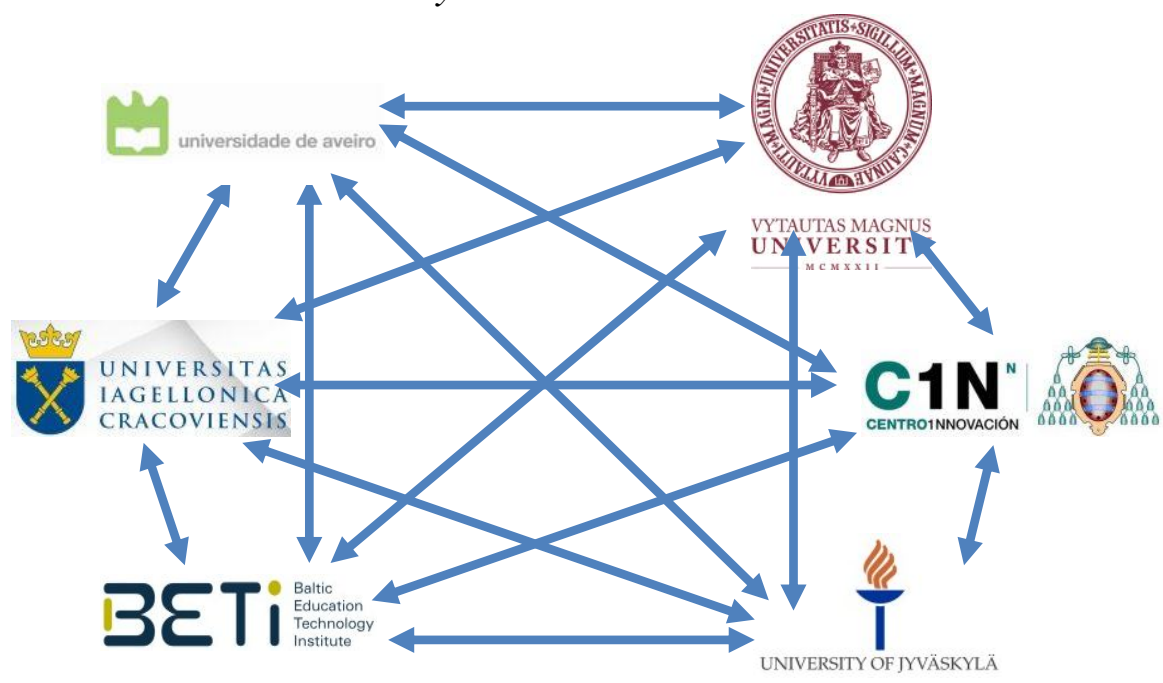

The following research methods were used in the research:

- a scientific literature review and document analysis were used to support the module "Virtual Learning in Higher Education" as a case study. Tools and assessment methods were defined, as well as their theoretical and empirical exploration analysed.

- a case study, during which 3 online surveys were used to identify what was required for the preparation of lecturers for virtual mobility (as communicative and collaborative learning activities, necessary for internationalisation of higher education institutions) implementation, as well as competences necessary for participants to participate in virtual mobility. The online survey data was analysed in order to define peculiarities of module organization, the competencies participants acquired and developed, and the recognition possibilities of the achieved learning outcomes at the participating universities. Data analysis method was descriptive interferential.

The research was implemented in five stages. The search, selection, and analysis of educational policy, juridical documents and scientific literature were performed at all stages in order to justify the virtual mobility case. A common empirical research design is represented in Table 1. 
Table 1 Empirical research design

\begin{tabular}{|l|l|l|l|l|}
\hline \multicolumn{2}{|c|}{ EMPIRICAL RESEARCH DESIGN } \\
\hline $\begin{array}{l}\text { Systemic } \\
\text { analysis of } \\
\text { documents, } \\
\text { legal acts } \\
\text { and } \\
\text { scientific } \\
\text { literature }\end{array}$ & $\begin{array}{l}\text { Study } \\
\text { module }\end{array}$ & $\begin{array}{l}\text { Research } \\
\text { instrument }- \\
\text { quearning in } \\
\text { qugher } \\
\text { Educationnaires } \\
\text { for teachers } \\
\text { and students }- \\
\text { preparation } \\
\text { preparation }\end{array}$ & $\begin{array}{l}\text { Study module } \\
\text { VLHE } \\
\text { delivery. } \\
\text { Research } \\
\text { performance } \\
\text { after the study } \\
\text { module }\end{array}$ & $\begin{array}{l}\text { Analysis and } \\
\text { systemic } \\
\text { analysis of } \\
\text { the content } \\
\text { of the } \\
\text { questionnaire } \\
\text { data, and } \\
\text { preparation } \\
\text { of the } \\
\text { research } \\
\text { report }\end{array}$ \\
& & & $5^{\text {th }}$ stage \\
\hline $1^{\text {st }}$ stage & $2^{\text {nd }}$ stage & $3^{\text {rd }}$ stage & $4^{\text {th }}$ stage \\
\hline Search, selection and analysis of educational policy, juridical documents and \\
scientific literature
\end{tabular}

The $1^{\text {st }}$ stage of the research. A systemic analysis of documents, legal acts and scientific literature was performed. The aim of the analysis was to create the background for the methodological research framework and prepare the research instrument.

The $2^{\text {nd }}$ stage of the research. A study module "Virtual Learning in Higher Education" as a case study of virtual mobility was prepared. Learning goals and outcomes were indicated, learning content prepared, technological and assessment tools and methods selected. All 6 participating institutions developed a joint study module consisting of 12 learning outcomes-based on 6 study submodules ( 8 academic hours each, using various learning scenarios and resources), including learning outcomes assessment strategy.

The module was of 6 ECTS (video lecturing, individual student work, teacher consultations and evaluation of learning outcomes). The aim of the Virtual Learning in Higher Education (VLHE) module was to enable students to plan and experience virtual mobility sessions by practicing video lecture participation, performing group and individual online activities, using and sharing virtual resources in a multicultural virtual learning environment. The teachers from the participating institutions formulated the learning outcomes which students were to acquire during the course and elaborated sub-modules during which these learning outcomes were to be reached (see Table 2).

The course curriculum content was developed using the Moodle virtual learning environment. Each participating institution prepared 1 sub-module which had to include compulsory readings, a student guide, activities, recommended resources, sub-module guidelines, and a sub-module discussion forum. 
Table 2 Virtual Learning in Higher Education module

\begin{tabular}{|c|c|c|}
\hline \multicolumn{3}{|c|}{ VIRTUAL LEARNING IN HIGHER EDUCATION MODULE } \\
\hline $\begin{array}{l}\text { Participating } \\
\text { institution }\end{array}$ & Sub -module & $\begin{array}{l}\text { Learning outcomes. } \\
\text { Students will be able to: }\end{array}$ \\
\hline $\begin{array}{l}\text { Jyväskylä } \\
\text { University }\end{array}$ & $\begin{array}{l}\text { Cultural Models } \\
\text { (week 1) }\end{array}$ & $\begin{array}{l}\text { 1. Understand culture models } \\
\text { and their application in } \\
\text { education. }\end{array}$ \\
\hline $\begin{array}{l}\text { Innovation } \\
\text { Centre of } \\
\text { University of } \\
\text { Oviedo } \\
\text { (UNIOVI) }\end{array}$ & $\begin{array}{l}\text { Collaborative Online } \\
\text { Learning } \\
\text { (week 2-3) }\end{array}$ & $\begin{array}{l}\text { 2. Know different technological } \\
\text { resources for collaborative } \\
\text { group work online. } \\
\text { 3. Demonstrate the skills needed } \\
\text { to facilitate collaborative group } \\
\text { work online. }\end{array}$ \\
\hline $\begin{array}{l}\text { Jagiellonian } \\
\text { University }\end{array}$ & $\begin{array}{l}\text { Information Literacy } \\
\text { (week 4-5) }\end{array}$ & $\begin{array}{l}\text { 4. Analyse online information. } \\
\text { 5. Create online materials. }\end{array}$ \\
\hline BETI & $\begin{array}{l}\text { Advanced Learning } \\
\text { Technologies (week } \\
6-7 \text { ) }\end{array}$ & $\begin{array}{l}\text { 6. Define the technologies and } \\
\text { standards used in distance } \\
\text { education. } \\
\text { 7. Apply learning management } \\
\text { systems based on these } \\
\text { standards. }\end{array}$ \\
\hline $\begin{array}{l}\text { Vytautas Magnus } \\
\text { University }\end{array}$ & $\begin{array}{l}\text { Learning Strategies } \\
\text { (week 8-9) }\end{array}$ & $\begin{array}{l}\text { 8. Compare learning styles and } \\
\text { learning strategies. } \\
\text { 9. Identify and apply online } \\
\text { resources in order to implement } \\
\text { learning strategies virtually. }\end{array}$ \\
\hline $\begin{array}{l}\text { Aveiro } \\
\text { University }\end{array}$ & $\begin{array}{l}\text { E- Assessment } \\
\text { Strategies } \\
\text { (week 10-11) }\end{array}$ & $\begin{array}{l}\text { 10. Design assessment strategies } \\
\text { for virtual learning. } \\
\text { 11. Use tools to support } \\
\text { scenarios of virtual learning. }\end{array}$ \\
\hline $\begin{array}{l}\text { Jyväskylä } \\
\text { University }\end{array}$ & $\begin{array}{l}\text { Cultural models } \\
\text { (week 12) }\end{array}$ & $\begin{array}{l}\text { 12. Apply the knowledge of } \\
\text { culture models to solve } \\
\text { problems caused by cultural } \\
\text { differences in Virtual Mobility. }\end{array}$ \\
\hline
\end{tabular}

The participating institutions agreed that each of them would have a session for 1 or 2 weeks on a topic. Sessions were organised in a synchronous (video conferences were organized each Friday) and asynchronous way (records of the videoconferences were available for students who could not participate in the videoconference). 
The $3^{\text {rd }}$ stage of the research. The research instruments - questionnaires for students and teachers were constructed. The structure of the questionnaires for students and teachers that were administered after the module was very similar. The questionnaire for teachers consisted of the following parts: general questions, lesson planning, virtual mobility organization and quality assurance, virtual mobility competence, and virtual mobility recognition. The questionnaire for students covered the following fields: personal data, learning outcomes/competence acquired, organizing virtual mobility, virtual mobility skills, and virtual mobility recognition.

The $4^{\text {th }}$ stage of the research consisted of 2 types of activities - delivery of a study module and research implementation.

The students from Vytautas Magnus University, University of Aveiro, Jyväskylä University, Kaunas University of Technology, Jagiellonian University, and Oviedo University were registered in the virtual learning environment (further VLE) Moodle. All study materials, such as descriptions of the module and submodules, content, presentation slides, scientific papers, links to web pages, etc., were uploaded in VLE. Students had to participate at 2-hour videoconference lectures staying at their home university each week. During the lectures, the teachers from the participating universities (depending on the module) were delivering their sub-module lecture, describing assignments that the students had to perform during the upcoming week, discussing various unclear issues and giving feedback on the performed assignments. All the lectures were recorded and accessible for students who could not participate in the videoconference as lecture records in VLE. So the students had the possibility to review the lecture records at home.

All module assignments for students were either individual or to be performed in national or international groups. There were five international groups that usually consisted of one participant from each institution. The international groups were stable for the entire module in order to create the possibility to communicate and collaborate for participants of various cultural backgrounds. The participants' assessment was performed after finishing each sub-module.

The research was performed after mobility sessions were implemented, this refers to both student and teacher online questionnaires.

The $5^{\text {th }}$ stage of the research. The content analysis of the obtained data and their statistical analysis were performed, and a research report was produced.

\subsection{Tools for virtual mobility}

"Virtual Mobility in Higher Education" module curriculum content was developed using the Moodle virtual learning environment (VLE). The module was divided into 6 parts. The first section of the module called "General Information about the Module" was left for general issues, and the following aspects were indicated in it: 
1. Two forums were created for organizational issues - "General Module Information Forum" (teachers provided important information to students) and "General Forum" (for both students and teachers - organizational issues were discussed).

2. Module Descriptions. General information about the module was presented in this section. The following information could be found here by students: the title of the subject, participating institutions, participating teachers, division of this module into sub-modules, module goals and learning outcomes, the language of the module, pre- requisites for this module, and its duration (months, hours, and credits).

3. Technical help. Technical help during the delivery of this module was provided. Either if students had problems with VLE Moodle or there were some problems with video conferences, they could contact the person responsible for the particular area. Both persons' contact details were available for all participants.

4. Pedagogical help. In this part, the contacts of all teachers who were delivering the module were listed. Since this module was divided into 6 sub-modules, the dates and teachers of every sub-module were identified.

5. Video conferences/ synchronous meetings. Every video conference was recorded and the link for the record was provided in VLE Moodle environment.

6. Time planning of the module was made in the calendar. Moodle has quite a functional tool for planning events, assignments and meetings. Since teachers posted their assignments using an assignment tool, the system added all the assignments to the calendar automatically. It was very convenient for students, because all the important dates and assignments were in one place.

There were a lot of technical possibilities for students to collaborate online, store their study results (a portfolio tool was installed for this purpose in VLE Moodle) and communicate with other international students. During this virtual course, a lot of tools where used. Students had the opportunity to use the virtual learning environment with its internal tools (forums, wiki, blogs, e-portfolio, mind maps, etc.), a web conferencing tool, a survey tool, and a recording tool.

The access to the curriculum was enabled at the Moodle virtual learning environment using networking services for educational institutions. The idea to apply this technological solution was derived from the need for the creation of a virtual campus for the participating universities. Therefore the Moodle networking service was established at all participating institutions - all users using Moodle virtual learning environment at home institution were able to access it and to enter to the Moodle network server using their institutional Moodle logins. For those institutions who decided not to use Moodle networking tool - usernames and passwords were created and sent to the institution's IT administrators. 


\section{Results}

Two different questionnaires were used for students and teachers, however, some of the questions were the same. Therefore most teachers' and students' answers, related to virtual mobility organizational issues and curriculum internationalization possibilities, could be discussed and compared. They cover such sections as the importance of tools and feedback methods, virtual mobility competences improved during the course, participants' opinions on virtual mobility after experiencing it, and its recognition possibilities in higher education institutions.

One of the ways to communicate and organize the learning process in virtual mobility is the use of ICT tools. Figure 2 shows the opinions of teachers and students on the important communication and collaboration methods and tools used in the module. All communication methods and tools were found important by participants (by $50 \%$ of participants or more), except social networks, rated as important only by $31 \%$ of teachers (see Fig. 2).

Figure 2 Importance of communication and collaboration methods and tools used in the module

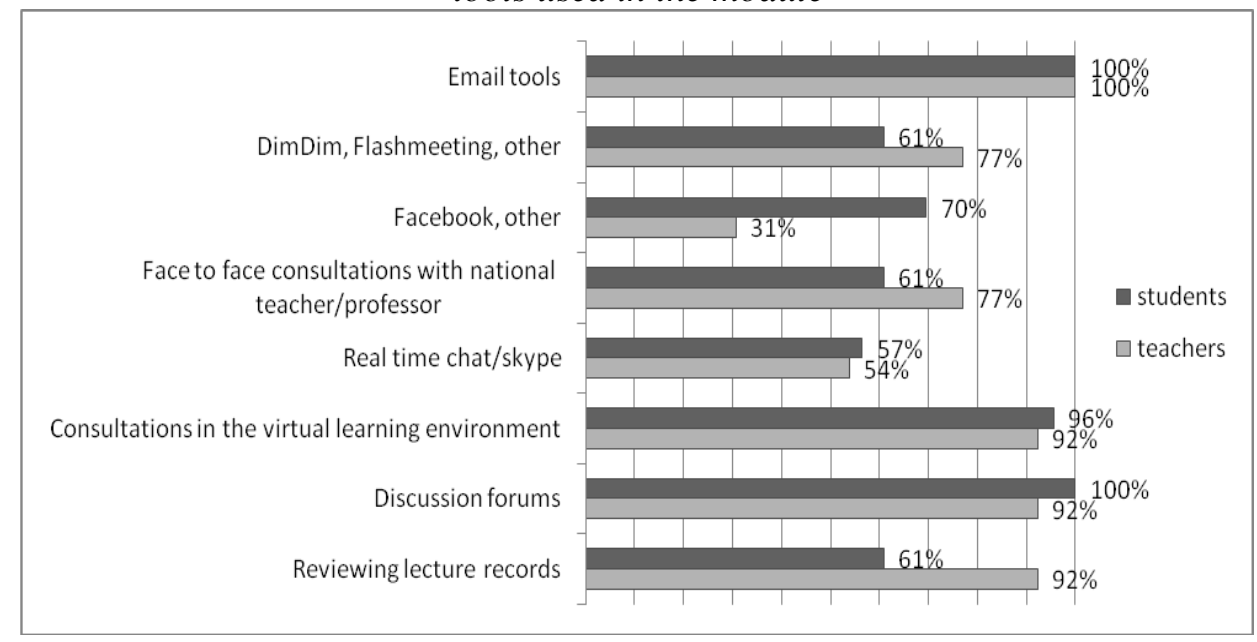

Email tools, discussion forums (both rated as very important), and consultations in the virtual learning environment (rated as important) were indicated as the most important ways of communication and collaboration (see Fig. 2). The importance of other methods and tools was perceived differently by students and teachers: reviewing lecture records, videoconferencing tools, and face to face consultations with a national teacher were considered to be more important by teachers than by students, and vice versa - social networks' importance was rated much higher by students than by teachers. 
Another important aspect in the organization of virtual mobility is providing feedback. We can assume that, according to most teachers and students, feedback was provided to both individuals and groups (see Fig. 3), though more teachers than students experienced individual feedback. A rather small number less than a half - of students and teachers declared that the way and time of giving feedback on one's learning outcomes was clearly stated. It leads us to the assumption that learners lacked some clearness in feedback on their improvement referring to their learning outcomes. This reveals the lack of teachers' preparedness for virtual mobility organization, having in mind that all the participating teachers were from traditional (not virtual) universities.

Only about one half of the teachers indicated that they provided self-assessment possibilities for students, but students did not feel a lack of them and indicated the provision of self-assessment possibilities in the module.

Figure $3 \quad$ Methods of feedback used in the module

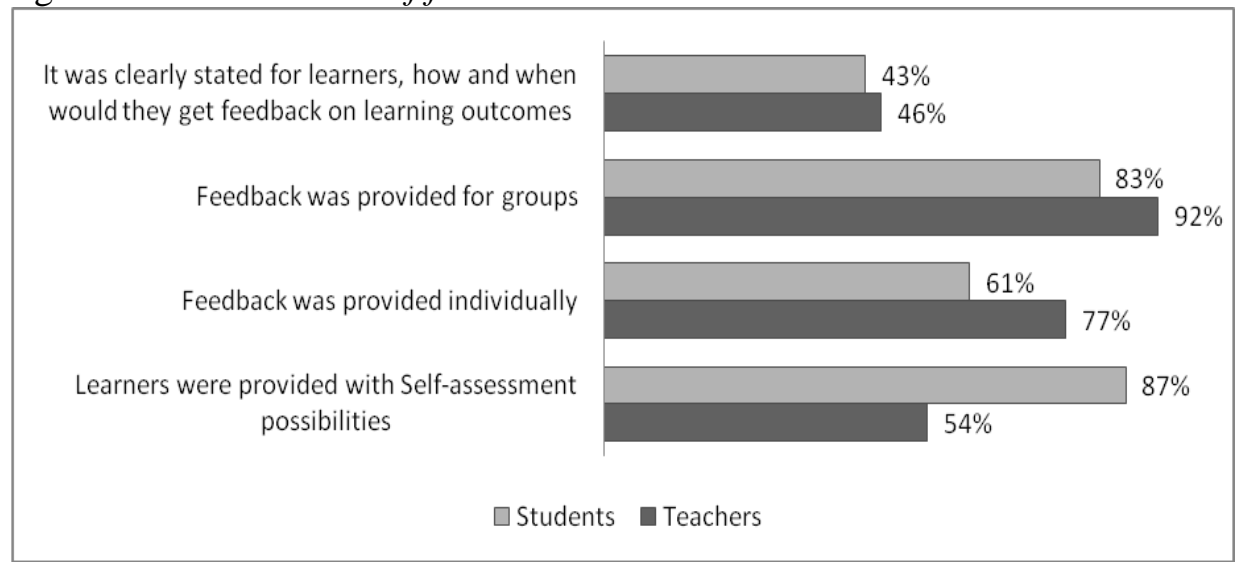

Although the virtual mobility experience was aiming at contributing more to the teachers' competences, their improvement is not possible if the students are not engaged. So while comparing student and teacher improvement in virtual mobility competences, a greater progress was seen in students' competences, as they spent the whole semester by virtual learning whereas the teachers were responsible for educational organization and lecture delivery only for 2 weeks. Some teachers commented that they would like to try teaching for more than 2 weeks of the virtual mobility course; they showed their interest in this form of virtual collaboration. Student and teacher improvement in virtual mobility competences and their comparison is shown in Figure 4. Some teachers admitted having not improved some of the competences while the students did it at least at a minimal level. 
Figure $4 \quad$ Improvement of teacher and student virtual mobility competences (improved categories in percentages)

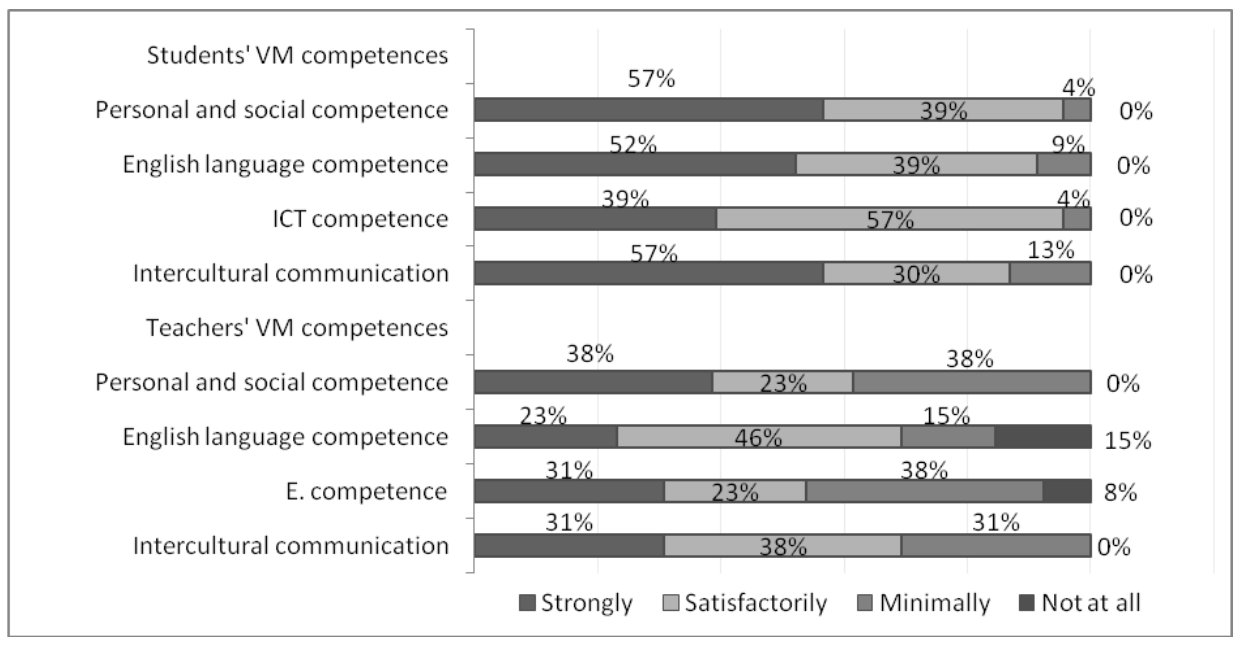

The surveys also aimed at the identification of the participants' attitude towards virtual mobility after they had experienced it (see Fig.5).

Figure $5 \quad$ Changes in student and teacher attitude after virtual mobility course (numbers of respondents)

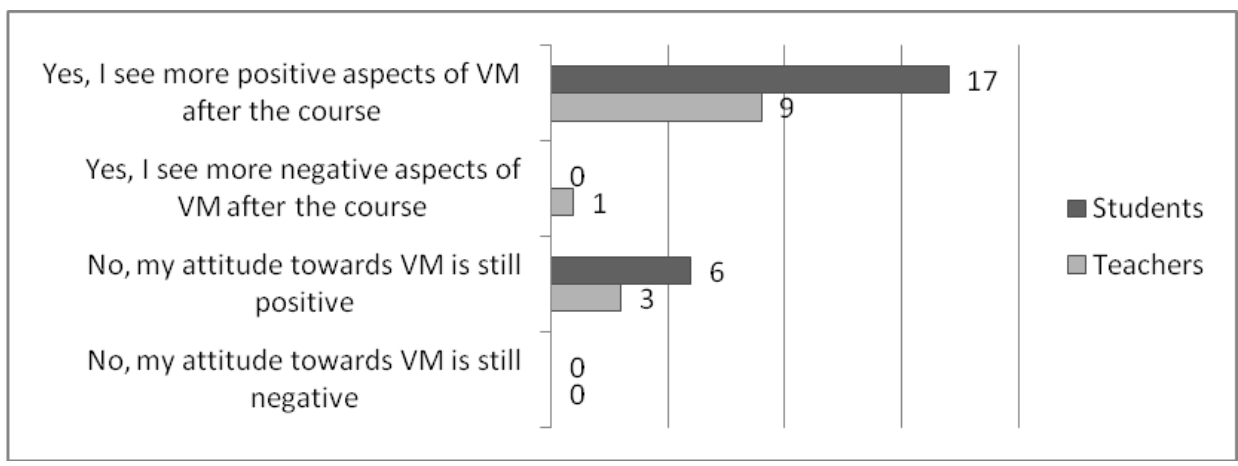

The participation in a virtual mobility course helped most of the students and teachers to better understand the virtual mobility concept and its realization from practice. The experience allowed most of the participants to see more of the positive aspects of virtual mobility (indicated by $72 \%$ participants), whereas one fourth $(25 \%)$ of the participants had not changed their attitude towards virtual 
mobility, but it remained positive. Only one teacher saw more negative aspects of virtual mobility after the virtual mobility course.

As results from the previously implemented analysis in the virtual mobility participating institutions on virtual mobility practices, there were no legal restrictions for the virtual mobility of teachers and students at any of the participating institutions. The VLHE module participants, being the respondents of the students' survey, were asked if the module would be recognized at their institution. So none of the students and only one teacher indicated seeing no restrictions for module recognition, but some students and half of the teachers were still not sure if the module would be or could be recognized at their HEIs. This indicates that virtual mobility accreditation and recognition is an institutional decision and it requires more coherent institutional awareness and guidance for administrative and educational departments to implement it. VMCOLAB project initiatives focus on the institutional awareness and students guidance issues (for more information, please see wmcolab.eu) while UBICAMP project (for more information, please see http://www.ubicamp.eu/) intends to mainstream virtual mobility at participating institutions by suggestions of comprehensive solutions to virtual mobility barriers.

To sum up, the comparative analysis of the students' and teachers' answers revealed, that all the methods and tools of communication and collaboration were more or less important while working in an international and intercultural virtual environment; as well as giving feedback to students - teachers indicated that they gave feedback to students in a variety of forms, but fewer students answered that they received feedback. As students spent more time learning than teachers teaching, students' virtual mobility competence improvement was greater than that of the teachers. Virtual mobility recognition possibilities indicated by the module participants were uncertain, varied between higher education institutions, and called for a more strategic approach on the side of the participating higher education institutions.

\section{Conclusions}

1. The existing initiatives, practices, and empirical research results acknowledge the fact that not only face-to-face academic learning is valued and that universities not only create knowledge, but they also build bridges between various cultures and create a new potential for the organization to offer an international experience for students and teachers. The reality suggests that universities, seeking to respond to the changes of the global economy, make their first steps and lack practice in organizing and implementing virtual mobility studies for those who cannot to leave the country, workplace or university due to various social, economic or personal reasons. 
2. The competences of higher education teachers and changes in teacher training are also faced with the upcoming challenges and require more strategic improvements. Designing a technology enhanced curriculum and the organizational process of teaching/learning for the purposes of international virtual mobility should be based on a certain methodology and theoretical dispositions.

3. The comparative analysis of student and teacher answers from the surveys revealed that all communication and collaboration methods and tools were important when working in a virtual environment. The importance of feedback for students was noticed and highlighted. The research results proved that intercultural communication competences during the virtual mobility program were improved both by students and their teachers, but as students spent more time learning than teachers delivering, so the students' virtual mobility competence improvement was greater than that of the teachers. All the competences improved by the virtual mobility participants contributed to the improvement of internationalization competence as well.

4. Fair virtual mobility recognition possibilities inspire discussions for more strategic institutional collaboration and for a qualitative approach. Additional possibilities should be provided and diverse learning environments created. The improvement of intercultural or other virtual mobility competences emphasises the importance of virtual mobility in order to promote international communication and to develop one's communication skills through cooperation with people from other countries and cultures. It also has an impact on internationalisation in higher education institutions.

Acknowledgement. The paper is based on the findings of the comparative research study „Virtual Mobility for Teachers and Students in Higher Education"(Eds. Teresevičienè, Volungevičienè, \& Daukšienè, 2011) and developments of UbiCamp: Integrated Solution to Virtual Mobility Barriers (Project ID: 526843-LLP-1-2012-ES-ERASMUS-ESMO) and VMCOLAB: European Co-Laboratory for the Integration of Virtual Mobility in Higher Education Innovation and Modernisation Strategies (Project ID: 527770-LLP-12012-1-BE-ERASMUS-ESMO).

\section{References}

BIJNENS, H. et al. Best practice manual. European Cooperation in Education through Virtual Mobility [online]. [viewed 22 October 2012]. Available from: http://www.europace.org/articles\%20and\%20reports/Being\%20Mobile\%20Man ual\%20-\%20Internet\%20version.pdf 
BIJNENS, H. and OP DE BEECK, I. Elearningeurope. info. from The Integration of Virtual Mobility in Europe [online]. 2006 [viewed 22 October 2012]. Available from:

http://www.elearningeuropa.info/directory/index.php?page=doc\&doc_id=7245\& doclng $=6$

BONINSEGNA, A. and DONDI, C. HUMANITIES Guidelines for the implementation of ODL and a VIRTUAL MOBILITY approach in Conventional Universities. DG XXII SOCRATES ODL Programme, Humanities project result. 1998.

BUNT-KOKHUIS, S. G. Academic Pilgrims: Faculty Mobility in the Virtual World. On the Horizon, 2001, 9 (1), 1-6.

OP DE BEECK, I. et al. Extending and supporting physical student mobility through virtual mobility. Nicosia (Cyprus), 2007.

PAWLOWSKI, J., HOLTKAMP, P. and KALB, H. Globalization Competencies in Information Systems and E-Learning. Workshop on Competencies for the Globalization of Information Systems in Knowledge-Intensive Settings. 1st International Conference on Software Business, Jyväskylä, Finland, 2010.

SPOT+ PROJECT team. Training Module 2: A Virtual Erasmus Student [online]. 2001 [viewed 22 October 2011]. Available from:

http://www.spotplus.odl.org/downloads/Training_module_2.pdf

HAYWOOD, D. et al. Student Mobility in a Digital World [online]. Final Report of the VICTORIOUS Project. 2007 [viewed 25 March 2012]. Available from: http://www.coimbra-

group.eu/victorious/VIC\%20Final\%20Report\%20print\%20version.pdf

TERESEVIČIENĖ, M., VOLUNGEVIČIENĖ, A. and DAUKŠIENĖ, E. (eds.) Virtual mobillity for Teachers and Students in Higher Education. Kaunas: Vytautas Magnus University, 2011.

UBICAMP. Integrated Solution to Virtual Mobility Barriers. (Project ID: 526843-LLP-1-2012-ES-ERASMUS-ESMO).

VALIUŠKEVIČIŪTĖ, A. et al. Methodology of student support in international placement and exchange situations. ESMOS WP5 report. ESMOS project: Enhancing Student Mobility through Online Support.

VAN DER WENDE, M. (ed.). Virtual Mobility: New Technologies and the Internationalization of Higher Education. Hague, Netherlands: Organization for International Cooperation in Higher Education (NUFFIC), 1998.

VMCOLAB: European Co-Laboratory for the Integration of Virtual Mobility in Higher Education Innovation and Modernisation Strategies. (Project ID: 527770-LLP-1-2012-1-BE-ERASMUS-ESMO).

VRIENS, M., et al. Virtual mobility as an Alternative or Complement to Physical mobility. EDULEARN conference proceedings. Barcelona, Spain, 2010. 